\title{
Mixed-mode Fracture of Adhesively Bonded Metallic Joints Under Quasi-Static Loading
}

\author{
Hafiz TA ${ }^{\mathrm{a}}$, Abdel Wahab $\mathrm{MM}^{\mathrm{b}, \star}$, Crocombe $\mathrm{AD}^{\mathrm{a}}$ and Smith $\mathrm{PA}^{\mathrm{a}}$ \\ ${ }^{a}$ Division of Mechanical, Medical and Aerospace engineering, \\ Faculty of Engineering and Physical Sciences, University of Surrey, \\ Guildford, Surrey,GU2 7XH, UK. \\ ${ }^{b}$ Department of Mechanical Construction and Production, Faculty of Engineering, \\ Ghent University, B-9000 Gent, Belgium \\ ${ }^{*}$ Corresponding author: Prof. Dr. Ir. Magd Abdel Wahab, \\ e-mail: magd.abdelwahab@ugent.be
}

\begin{abstract}
Quasi-static tests have been carried out to characterise mixed-mode fracture using a Double Cantilever Beam (DCB) specimen. The DCB consists of equal thickness mild steel adherends bonded with FM-73M epoxy adhesive and is tested under pure mode I, pure mode II and a range of mode mixity conditions, using a relatively simple loading fixture. The test method is analysed using closed-form and finite element methods, which agree well provided that the adhesive deformation is considered. The strain energy release rate components at fracture are presented in a conventional $G_{I}$ (mode I) - $G_{\text {II }}$ (mode II) failure plot using closed-form Linear Elastic Fracture Mechanics (LEFM) methods reported previously in the literature. The results showed that the strain energy release rate is enhanced in the situation of the mode II (in-plane shearing) dominated mixed mode condition as compared to the mode I (opening mode) dominated mixed mode.
\end{abstract}

Keywords: Mixed-mode loading, Strain energy release rate (SERR), FEA, Linear Elastic Fracture Mechanics (LEFM) 


\section{Nomenclature}

$a=$ Crack length

$B=$ Width of the adherend

$E=$ Tensile modulus of the adherend

$F=$ Load applied to the jig from the test machine

$F_{1}=$ Load acting on the upper adherend

$F_{2}=$ Load acting on the lower adherend

$G_{I}=$ Mode I contribution of strain energy release rate (SERR)

$G_{I I}=$ Mode II contribution of strain energy release rate (SERR)

$h=$ Thickness of the adherend

$M_{1}=$ Moment acting on the upper adherend

$M_{2}=$ Moment acting on the lower adherend

$M_{\mathrm{I}}=$ Mode I component of moment acting on the sample

$M_{\mathrm{II}}=$ Mode II component of moment acting on the sample

$S_{1}, S_{2}, S_{3}$ and $S_{4}=$ Distances between support points in the loading jig

$t=$ Thickness of the adhesive

$\vartheta=$ Poisson's ratio of the adherend

\section{Introduction}

The use of adhesive bonding is becoming much more widespread in recent years as the advantages it offers over traditional joining techniques are becoming more widely accepted. This has led to the use of bonding in a range of sectors which includes aerospace, automobiles, electrical, electronics, packaging and shoe industries etc. A particular issue with the integrity of adhesive joints is the presence of cracks and flaws in the as-manufactured adhesive bond-line. The presence of these defects, at least at some scale, appears inevitable and the propagation of such cracks/flaws has the potential to affect the service life of the adhesively bonded joints and even to cause catastrophic failure of bonded structures in service. Hence a better understanding of crack propagation behaviour under realistic types of combined (direct and shear stress components) service loading is an important aspect of evaluating the potential performance of adhesively bonded joints. 
In principle, crack propagation can be described using a fracture mechanics approach [1]. In brittle homogeneous materials, a crack subjected to mixed mode loading will kink in such a way that the crack tip tends to become oriented at right angles to the tensile stress component thereby growing under mode I loading [2]. However, in bonded joints under arbitrary loading conditions, the crack is often constrained within the adhesive layer and can therefore be made to grow, at least macroscopically, in the plane of the applied mode II (for shear) or mixed-mode (for tension and shear) loading [3]. Much work has been published to characterise the performance of adhesives joints under mode I loading, but on its own this does not provide a basis for conservative design under more complex loadings. Hence the need for mixed-mode fracture characterisation becomes unavoidable.

Many researchers have used a range of experimental techniques to characterise mode I, mode II and mixed mode I/II fracture of adhesive joints and composite laminates, but none of these approaches [e.g. 4-10] provide a method of characterising material response over the entire range of mode mixities from pure mode I to pure mode II. The method used by Fernlund and Spelt [3] appears to be one of the few approaches [11-13] that do achieve this and in that respect it appears surprising that their technique has not been adopted more widely.

Hence in the present work, a simple loading jig was designed and manufactured, building on the work in [3]; the jig enables quasi-static fracture testing of a Double Cantilever Beam (DCB) type specimen over the entire mode-ratio range from pure mode I to pure mode II and will also be used for fatigue testing in the future. The structure of the paper is as follows. In the next section the design and manufacture of the jig are discussed, together with closed-form and finite element analyses that enable the strain energy release rate components to be determined. The jig is then used to characterise the behaviour of joints, consisting of mild steel adherends bonded with FM-73M epoxy adhesive, under quasi-static loading. The strain energy release rate components at fracture are presented in a conventional $G_{\text {I }}$ (mode I) - $G_{\text {II }}$ (mode II) failure plot. The results are discussed and compared with other studies in the literature. 


\section{Design and Analysis of the Test Arrangement}

\subsection{Test Method}

The purpose of the loading jig is to facilitate mixed-mode fracture testing of adhesively bonded DCB joint specimens over a wide range of mode mixities from pure mode I to pure mode II. The jig shown in Fig. 1, which is very similar to that in [3], consists of a link arm system that allows the ratio of the forces $F_{1}$ and $F_{2}$ acting on the upper and lower adherends of the test specimen respectively to be varied by altering the applied load $(F)$ position along the upper link, i.e. by varying the distances $S_{1}$ and $S_{2}$. The column at the right hand end of the specimen enables the specimen to be supported prior to application of load and prevents out of plane displacement during the test. The links in the loading jigs are made of mild steel and dowel pins are used to enable the geometry position to be changed easily.

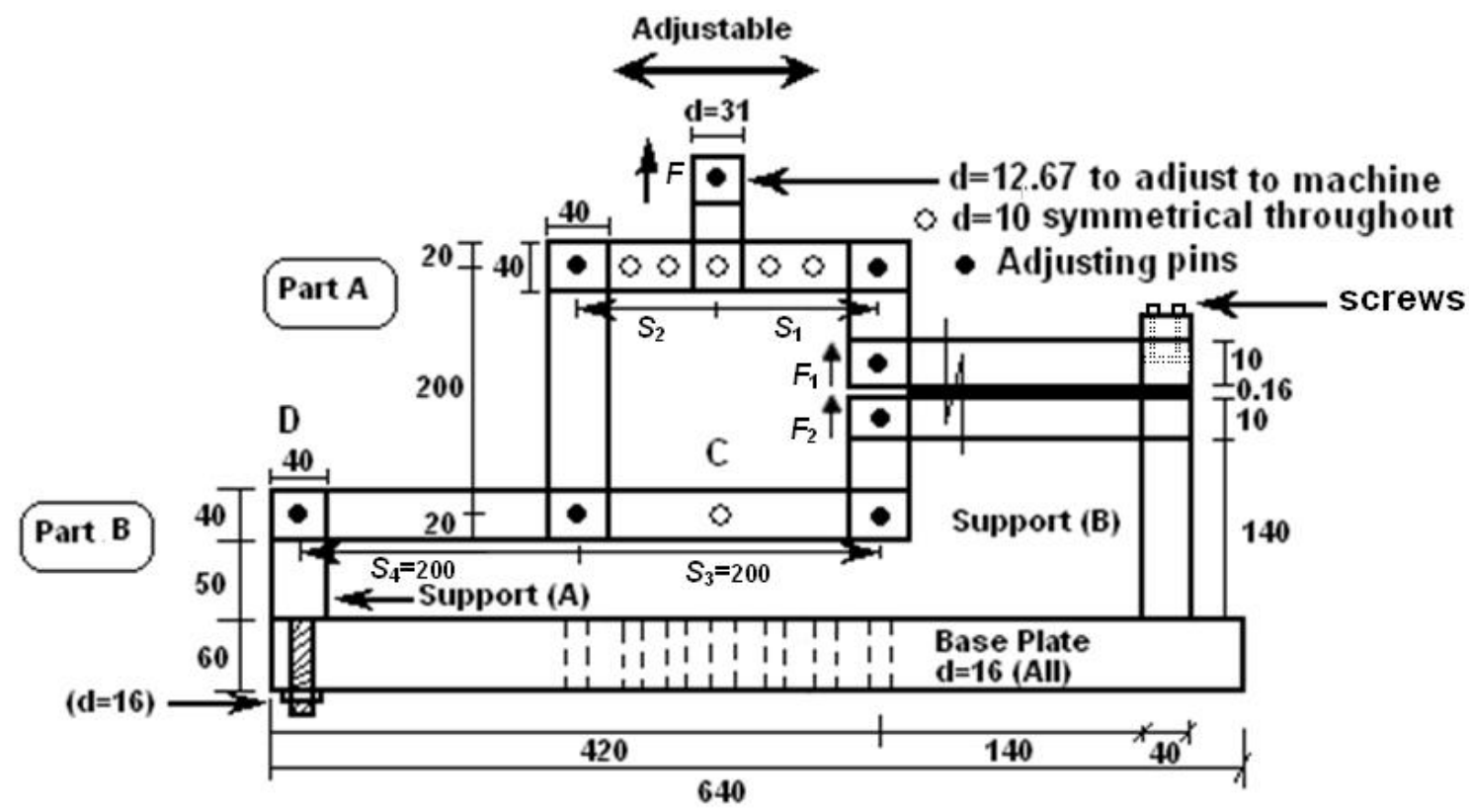

Figure 1 Schematic Diagram of the Load Jig (all dimensions in mm) 
The uppermost vertical bar is attached to the mechanical testing platform using a pin arrangement. The upper horizontal drilled bar (part A) is $240 \mathrm{~mm}$ long in total and of $40 \mathrm{~mm}$ height and $20 \mathrm{~mm}$ width. It is designed with holes (from right to left) at 45 , $70,100,133.3,165$ and $200 \mathrm{~mm}$ measured from the centre of the right-hand adjusting pin. These holes enable different mode ratios to be applied. The lower bar (part $B$ ) is connected to the base plate by Support (A) at one of two locations: either through a pin at $D$ (i.e. the configuration shown in Fig. 1) or through a pin at $C$. The $16 \mathrm{~mm}$ diameter holes in the base plate enable the jig to be attached to the base of the machine; these base plate holes are aligned with the holes in part A to ensure alignment while applying load during testing.

The remainder of this sub-section considers the simple mechanical analysis of the loading jig.

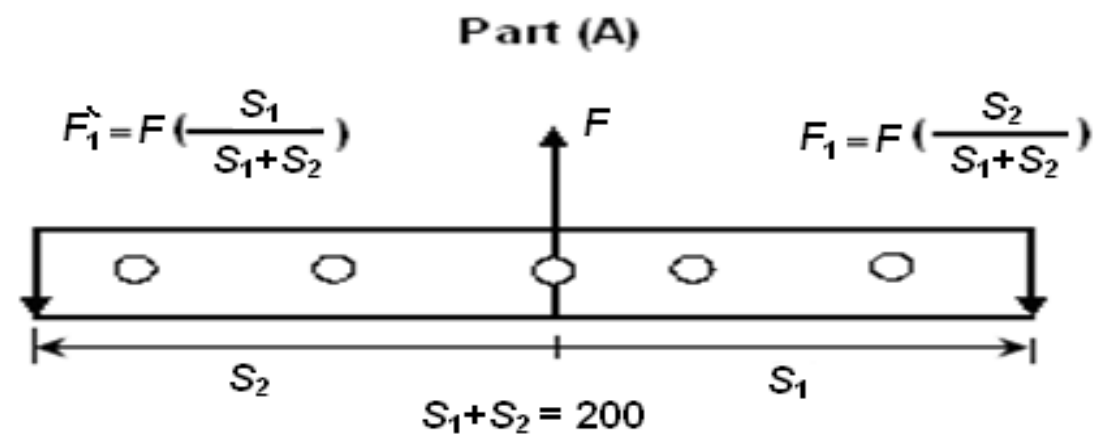

Figure 2. Resolution of Forces for Upper Horizontal Drilled-Bar

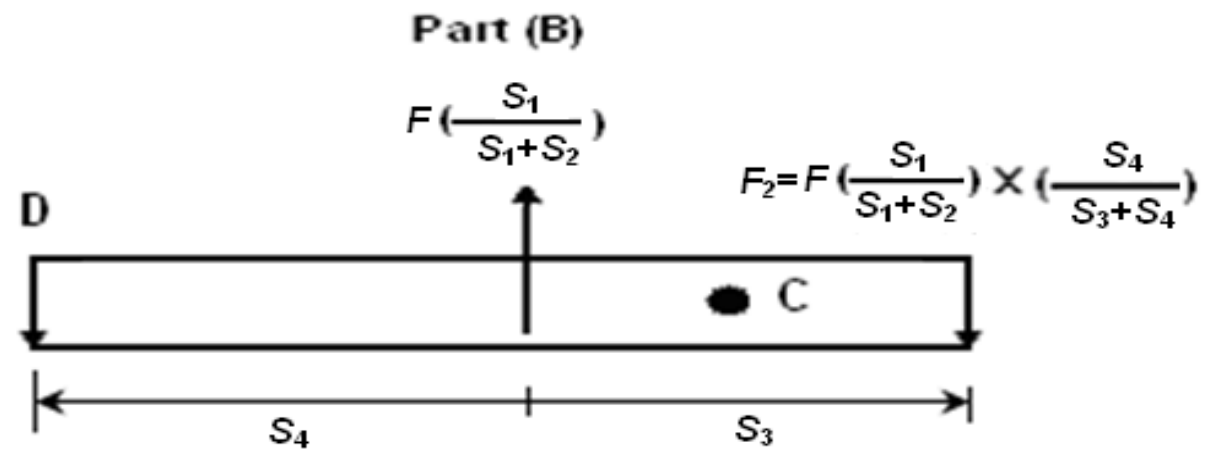

Figure 3. Resolution of Forces for Lower Horizontal Bar when connected at D 


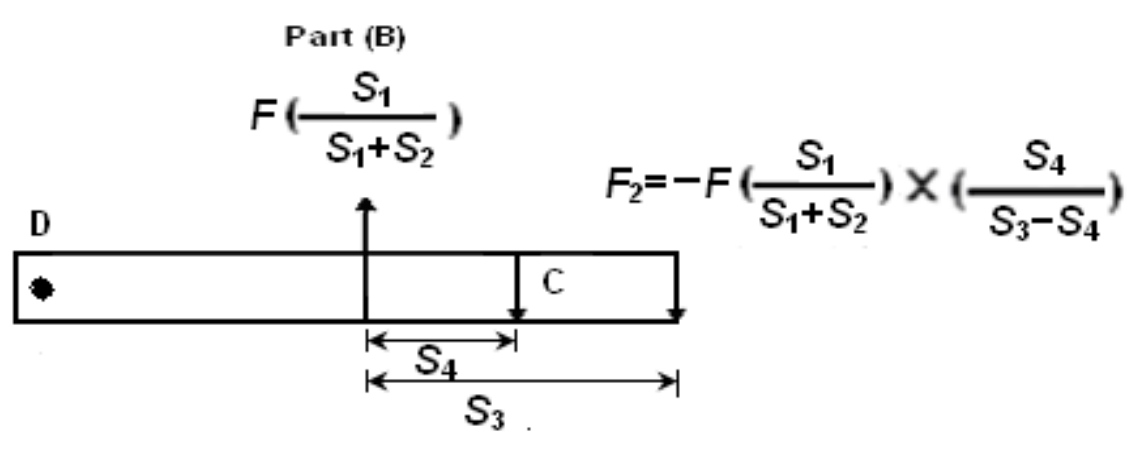

Figure 4. Resolution of Forces for Lower Horizontal Bar when connected at C

The loading jig is statically determinate and the specimen loads $F_{1}$ and $F_{2}$ are calculated based on conditions of mechanical equilibrium, neglecting shear deformation and assuming that the adhesive layer of the test specimen is very thin (typically $0.16 \mathrm{~mm}$ in the experiments reported later in this paper).

It is necessary to take care regarding the sign convention. In particular $F_{1}$ and $F_{2}$ on the test specimen (Fig 1) are taken as positive when they act in the same direction as the applied load $F$. When the Support (A) in Part $B$ is attached by the pin at $D$ as in Fig. 1, equilibrium of the upper and lower bars (Figs. 2 and 3) gives

$$
\begin{aligned}
& F_{1}=F \times\left(\frac{S_{2}}{S_{1}+S_{2}}\right) \\
& F_{2}=F \times\left(\frac{S_{1}}{S_{1}+S_{2}}\right)\left(\frac{S_{4}}{S_{3}+S_{4}}\right)
\end{aligned}
$$

When the Support (A) in Part B is attached by the pin at C, we find (Figs. 2 and 4) that $F_{1}$ remains unchanged, but now:

$$
F_{2}=-F \times\left(\frac{S_{1}}{S_{1}+S_{2}}\right)\left(\frac{S_{4}}{S_{3}-S_{4}}\right)
$$

Having established the basic relationship between the applied forces, this can be used to find the required configuration of the jig in order to produce a given mode ratio. 
For pure mode I loading of the joint the applied forces $F_{1}$ and $F_{2}$ must be equal in magnitude and opposite in direction i.e. $F_{1}=-F_{2}$. With the pin at $\mathrm{C}$, it follows from equations (1) and (3) that for mode I

$$
F\left(\frac{S_{2}}{S_{1}+S_{2}}\right)=F\left(\frac{S_{1}}{S_{1}+S_{2}}\right)\left(\frac{S_{4}}{S_{3}-S_{4}}\right)
$$

From equation (4) it is clear that the condition for pure mode I is satisfied when the load is applied centrally to Part A so that $S_{1}=S_{2}$ and further that Part B is attached to the base through locating Support $A$ at position $C$ so that $S_{4}=0.5 S_{3}$.

For mode II condition, there are two loading scenarios which will produce mode II for identical adherend thicknesses. One is when $F_{1}=F_{2}$ and the other is when $F_{1}$ is zero and a shim transmits half of $F_{2}$ to the upper adherend. These are achieved by pinning support $A$ at position $D\left(S_{4}=S_{3}\right)$ and then having either $S_{1}=133.3$ and $S_{2}=66.7$ (to give $F_{1}=F_{2}$ ) or $S_{2}=0$ (to give $F_{1}=0$ ).

Other geometries enable different mode mixities to be achieved. For support $A$ at position $D$, from combining equations (1) and (2) we have:

$$
\frac{F_{1}}{F_{2}}=\frac{S_{2}}{S_{1}}\left(\frac{S_{3}+S_{4}}{S_{4}}\right)
$$

While on the other-hand, for support $A$ at position $C$, from combining equations (1) and (3) we have:

$$
\frac{F_{1}}{F_{2}}=-\frac{S_{2}}{S_{1}}\left(\frac{S_{3}-S_{4}}{S_{4}}\right)
$$

Equations 5 and 6 can be further reduced recognising that when the support $A$ is at position $D, S_{4}=S_{3}$, and when it is at position $C, S_{4}=0.5 S_{3}$. The various pin arrangements and support conditions enable a wide range of intermediate mode mixities to be achieved.

In the next sections we consider, first analytically and then numerically (using FEA) the strain energy release rates corresponding to the different load ratios. 


\subsection{Closed-form analysis of the energy release rates:}

There are many studies, e.g. [6] and [7], which confirm that mixed mode fracture is controlled by a function of the energy release rate components rather than simply the total strain energy release rate and further that the form of the function may vary with the adhesive type (in "brittle" systems, the mode I component may dominate, while in "tough" systems both components make a contribution). Hence any analysis of the test configuration needs to take this into account and to partition the loading into the mode I and mode II components.

To analyse the configuration used in the present study, we make use of the work of Williams [14], who considered the general case of a cracked DCB with arms of unequal equal thickness, acted on by moments $M_{1}$ and $M_{2}$ as shown in Fig. 5 . Note that in the present work the arms were of equal thickness ( $h$ ) and so the analysis has been simplified to reflect this.
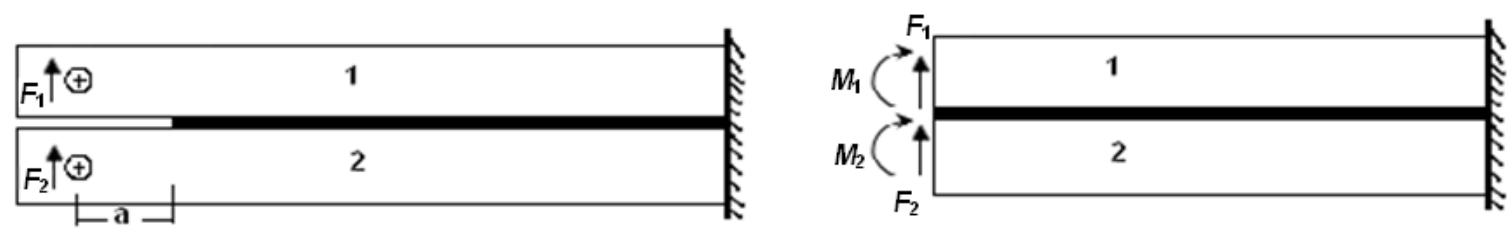

Figure 5 Double Cantilever Beam Test

We write:

$$
\begin{aligned}
& M_{1}=F_{1} \mathrm{a} \\
& M_{2}=F_{2} \mathrm{a}
\end{aligned}
$$

Separating the applied loading into mode I and mode II components, $M_{\mathrm{I}}$ and $M_{\mathrm{II}}$, requires that:

$$
M_{\mathrm{I}}=\frac{M_{1}-M_{2}}{2}
$$




$$
M_{\mathrm{II}}=\frac{M_{1}+M_{2}}{2}
$$

Therefore, the energy release rate components for the present case follow from [16] as:

$$
\begin{aligned}
& G_{\mathrm{I}}=\frac{12 M_{\mathrm{I}}^{2}}{B^{2} \mathrm{E} h^{3}}\left(1+\frac{1+\mathrm{v}}{5}\left(\frac{\mathrm{h}}{\mathrm{a}}\right)^{2}\right) \\
& G_{\mathrm{II}}=\frac{9 M_{\mathrm{II}}^{2}}{B^{2} \mathrm{E} h^{3}}
\end{aligned}
$$

Where E, $v, \mathrm{~h}, \mathrm{~B}$ are respectively the tensile modulus, Poisson's ratio, height and width of the adherend.

The second term in equation (11) for GI represents a correction for the shear contribution.

This method does not include the elastic behaviour of the adhesive bond-line, which has been shown to influence the fracture energy of the joint [15]. A further term [16] is introduced to take this adhesive effect into account:

$$
\lambda_{\sigma}^{4}=\frac{6}{h^{3} t} \frac{E_{\mathrm{a}}^{\prime}}{E}
$$

In equation (13) $1 / \lambda_{\sigma}$ serves as a length scale of the crack problem and $E_{\mathrm{a}}^{\prime}$ is $E_{\mathrm{a}} /$ (1$v_{a}^{2}$ ) the plane strain modulus of the adhesive. The expressions for the energy release rate components become.

$$
\begin{aligned}
& G_{\mathrm{I}}=\frac{12 M_{\mathrm{I}}^{2}}{B^{2} E h^{3}}\left(1+\frac{(1+v)}{5}\left(\frac{h}{a}\right)^{2}\right)\left(1+\frac{1}{\lambda_{\sigma} a}\right)^{2} \\
& G_{\mathrm{II}}=\frac{9 M_{\mathrm{II}}^{2}}{B^{2} E h^{3}}\left(1+\frac{1}{\lambda_{\sigma} a}\right)^{2}
\end{aligned}
$$


Of the two correction terms, the effect of the shear contribution turns out to be relatively minor - typically less than $4 \%$ of the moment term for the geometries used in the course of the present work. In the next section the loading is analysed using FEA.

\subsection{Finite Element Modelling}

A two dimensional (2-D) linear elastic finite element analysis of the bonded DCB geometry was carried out to validate the analytical expressions for $G_{I}$ and $G_{I I}$ introduced in the previous section. The study used $2^{\text {nd }}$ order 8-noded quadrilateral elements, as these elements generate more accurate results for mixed (quadrilateral-triangular) automatic meshes. Plane strain condition was assumed, to represent the constraint experienced by the thin adhesive layer confined between much stiffer adherends. The assumption of plane strain elastic modulus of the adhesive is also implicit in equation (13). The effect of any residual stresses is not considered in the analysis.

The overall mesh is shown in Figure 6. Load was applied at the left end of the joint, with the joint constrained in the vertical direction at its right end. The material responses were taken as linear elastic and isotropic using material constants reported in Table $1[17,18]$. The analysis confirmed that the stresses in the adherends were below yield and there was no evidence of adherend plasticity during the experiments. 


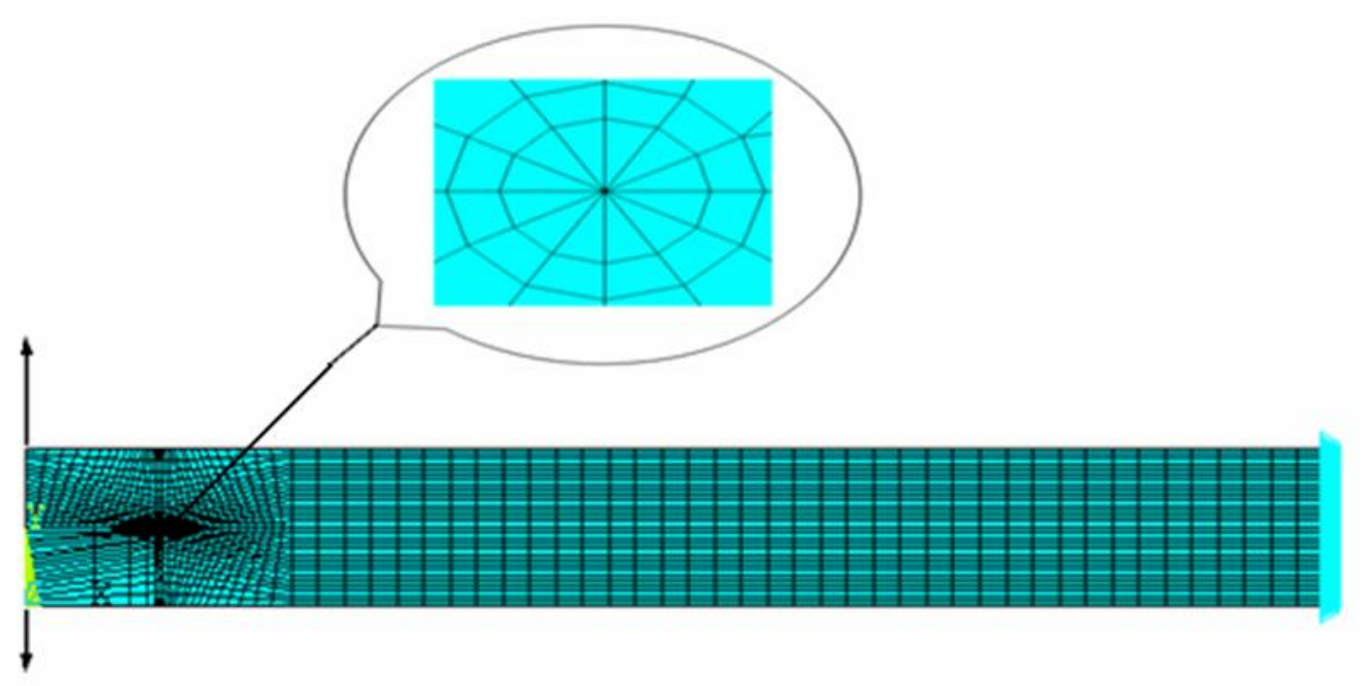

Figure 6 FE Model for bonded DCB specimen and detail showing elements at adhesive-adherend interface

Table 1 Elastic properties of materials

\begin{tabular}{|ccc|}
\hline Material & Young Modulus (GPa) & Poisson's ratio \\
\hline Mild Steel & 210 & 0.30 \\
FM-73M & 2 & 0.38 \\
\hline
\end{tabular}

The strain energy release rate components were calculated using the Virtual Crack Closure Technique (VCCT) technique, a well established fracture mechanics approach for analysing progressive crack growth in linear elastic problems. This approach [19] was implemented using crack tip elements [20]. The boundary conditions and crack length along with other specifications were kept exactly same as of those used in the experiments. The crack was introduced on the interface (between lower adherend and adhesive) as Abdel Wahab [21] showed that in most of the cases interfacial failure is observed for a very thin adhesive layer $(<0.5 \mathrm{~mm})$ and in the present case the adhesive layer thickness is $0.16 \mathrm{~mm}$. In this way, the 
analysis determines the energy release rate for crack growth in the adhesive, close to the adherend/adhesive interface. Figure 7 shows the deformed mesh for geometry with a mode mixity ratio $\left(G_{\mathrm{II}} / G_{\mathrm{I}}\right)$ of 0.22 . It is clear that the deformation comprises both opening and sliding modes. Figure 8 shows the reference points in and around the crack tip and the corresponding terminology for the local forces and displacements.

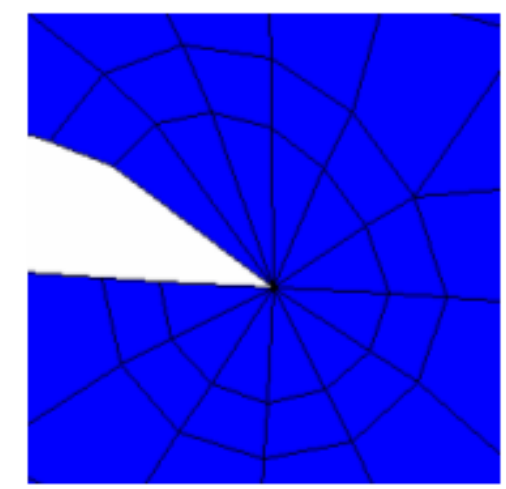

Figure 7 Deformed shape of FEA model at load $\operatorname{ratio} F_{1} / F_{2}=-3.44$

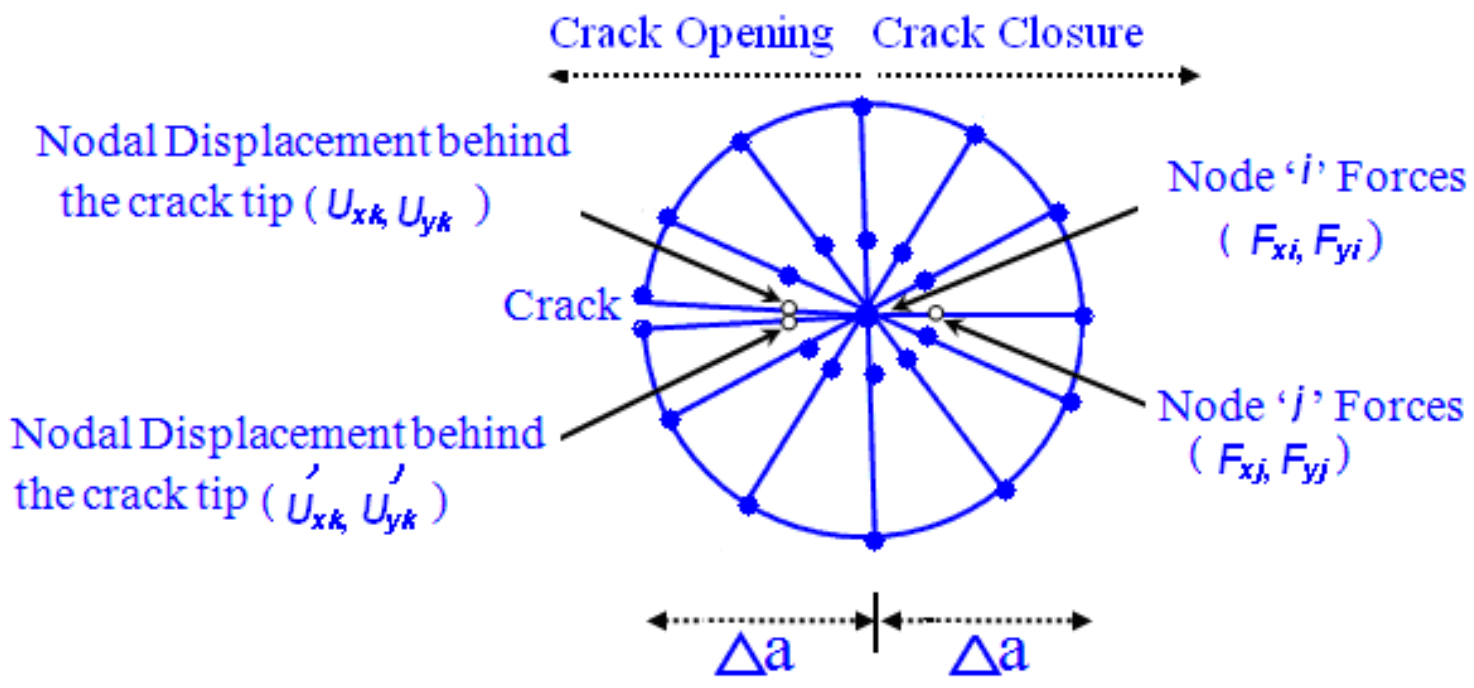

Figure 8 Nodes and elements around a crack tip, after [19]

The following expressions [19] are then used to calculate the mode I and mode II energy release rate components.

$$
G_{I}=\frac{\left(U_{y k}-U_{y k}^{\prime}\right)}{\Delta a}\left[F_{y j}+(1.5 \pi-4) F_{y i}\right]
$$




$$
G_{\text {II }}=\frac{\left(U_{x k}-U_{x k}^{\prime}\right)}{\Delta a}\left[F_{x j}+(1.5 \pi-4) F_{x i}\right]
$$

where $\Delta a$ is equal to the crack tip element length and $\left(F_{x i}, F_{y i}\right),\left(F_{x j}, F_{y j}\right)$ are the crack closure forces at node ' $i$ ' and ' $j$ ' respectively and $\left(U_{x k}, U_{y k}\right),\left(U_{x k}, U_{y k}\right)$ are for the nodal displacement behind the crack as shown in figure 9 .

\section{Experimental}

\subsection{Sample manufacture}

The DCB samples were prepared using FM-73M OST(one-side tacky) toughened epoxy film adhesive, obtained from Cytec Engineering Materials. Epoxy resin thermosetting adhesives, such as FM-73M, give good durability when bonding metals and are suitable also for bonding structural composite systems. Mild steel adherends were prepared with dimensions $200 \mathrm{~mm} \times 15 \mathrm{~mm} \times 10 \mathrm{~mm}$ (Figure 9) and $200 \mathrm{~mm} \times 15 \mathrm{~mm} \times 7 \mathrm{~mm}$. The latter adherend dimensions were used for mode mixities $\left(G_{\mathrm{II}} / G_{\mathrm{I}}\right.$, based on equations 14 and 15$)$ of 2.22 and 6.22 and for pure mode II, so as to avoid the possibility of loading jig fracture. In order to reduce the possibility of interfacial failure of the joint (as opposed to cohesive failure in the adhesive), the adherends were grit-blasted, using $50 \mu \mathrm{m}$ white alumina in a grit blasting facility operating at a pressure of 5.5 bar. After grit-blasting, the adherends were degreased with acetone so that any residual grit was removed.

The film adhesive was cut to size and then the joints were prepared following the recommended procedure. Metal shims were used to control the bond line thickness, giving a nominal value of $0.16 \mathrm{~mm}$. Mould release was applied to the shims so that they could be removed easily from the joint after the adhesive had been cured. The joints were clamped individually in a jig. Mould release was also applied to the columns of the jig in contact with the joint.

The top plate of the jig was weighted to apply a modest pressure to the joint (0.28 $\mathrm{MPa}$ ) and the jig was then placed in an air-oven. The cure cycle followed was in accordance with the data sheet from the adhesive manufacturer - a heating cycle up to 120 degrees $C$ in 30 minutes followed by a hold for 60 minutes and then leaving in the oven with door shut until the temperature reaches room temperature. After 
samples had been cured, they were stored in a desiccator and they were tested typically one to two days after manufacturing.

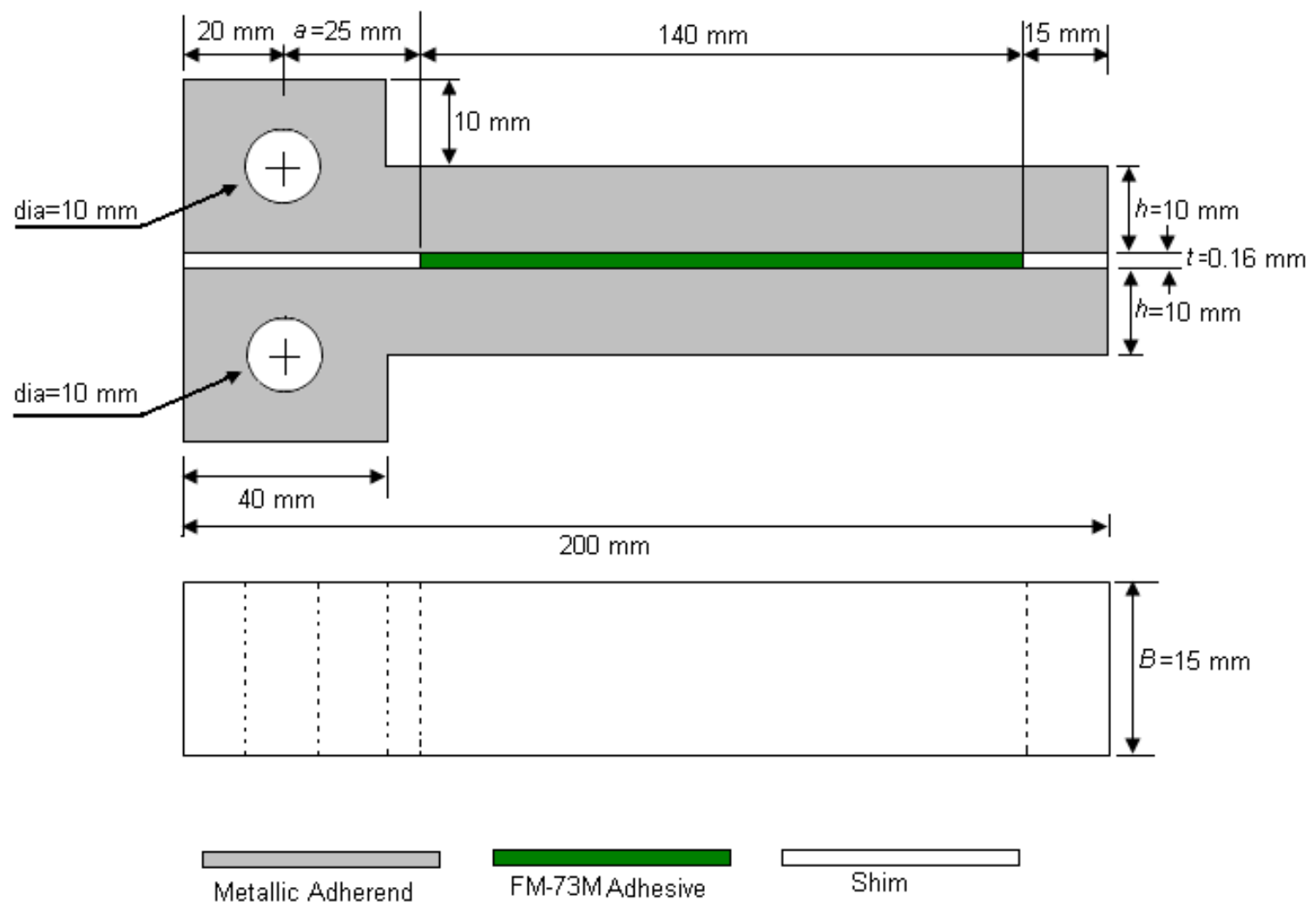

Figure 9 Bonded DCB specimen geometry

\subsection{Mechanical Testing}

Quasi-static tensile testing of the joints was carried out using the jig described in section 2.1, mounted on an Instron 5500R (frame 1175) testing machine, Fig. 10, driven by the Instron Merlin software [22]. A $100 \mathrm{kN}$ load cell was used and tests were performed using a crosshead displacement rate of $0.5 \mathrm{~mm}$ per minute. The data acquisition rate was $2 \mathrm{~Hz}$. Specimens were loaded to failure without interruption and at the end of the test the load and displacement data were transferred into a spreadsheet for analysis.

In addition to pure Mode I and pure Mode II testing, different intermediate mode mixities $\left(G_{\mathrm{II}} / G_{\mathrm{I}}\right.$, based on equations 14 and 15$)$ starting from $0.07,0.09,0.22,0.72$, 
$1.29,2.22$ and 6.62 were investigated. For each test case, a minimum of three tests were carried out.

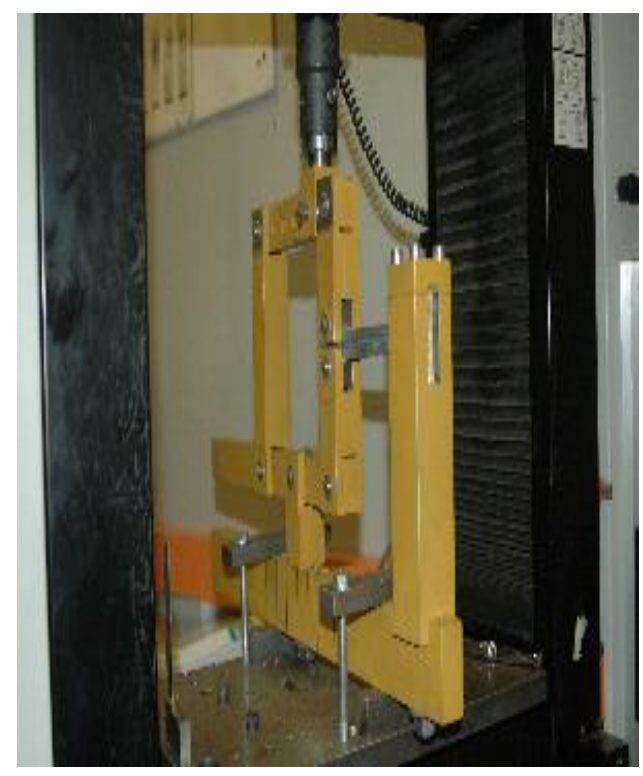

Figure 10 Loading jig mounted in the test machine

\section{Results and Discussion}

Figure 11 shows a typical load-crosshead displacement curve for one test specimen. All the samples tested were essentially linear elastic to failure.

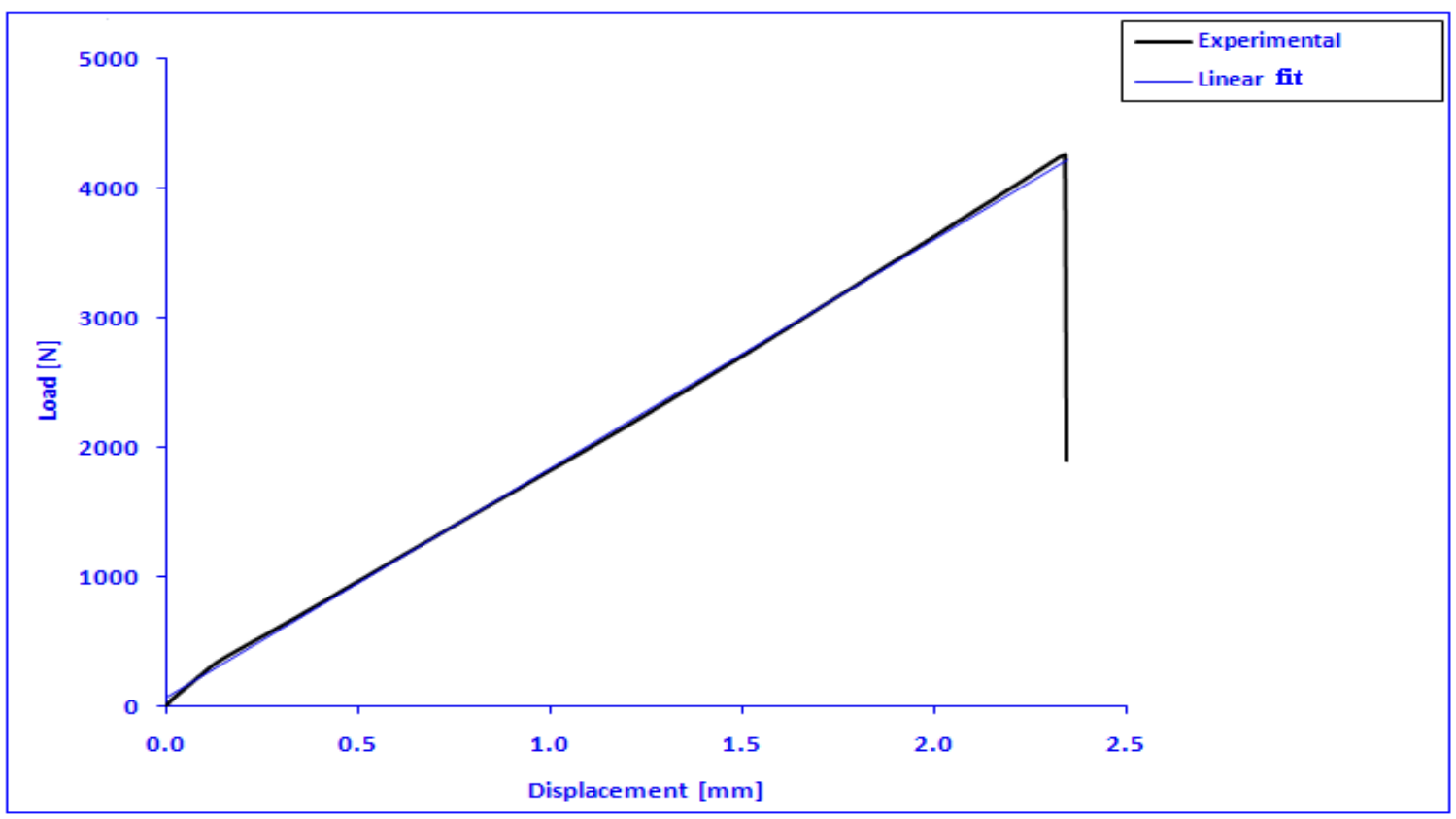

Figure 11 Typical load-crosshead displacement curve for a specimen with a nominal mode mixity of 0.09 , based on equations (14) and (15) [see Table 2 and 3] 
After testing, the fracture surfaces were examined and it was observed that all the joints exhibited cohesive failure as shown in figure 12 (higher magnification images would be needed to examine the failure mechanism, but the point to demonstrate here is that the failure is essentially cohesive).

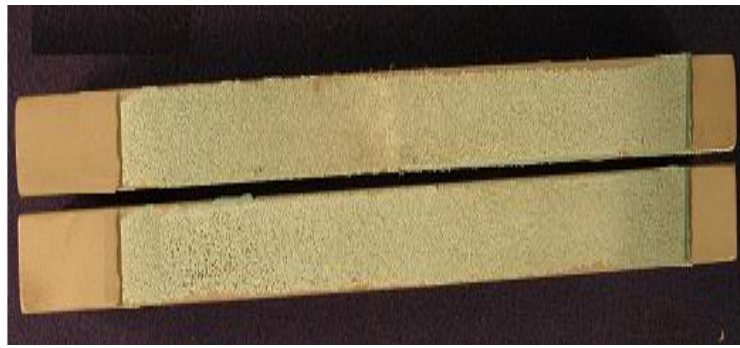

(a) Pure Mode I

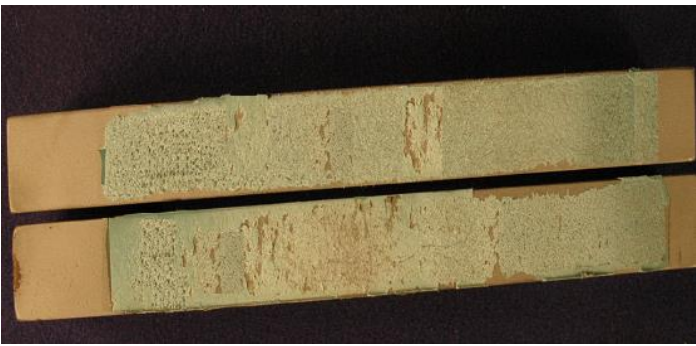

(b) Mode mixity $\left(G_{\mathrm{II}} / G_{\mathrm{I}}\right.$, eqns $\left.14 \& 15\right)$ of 0.09

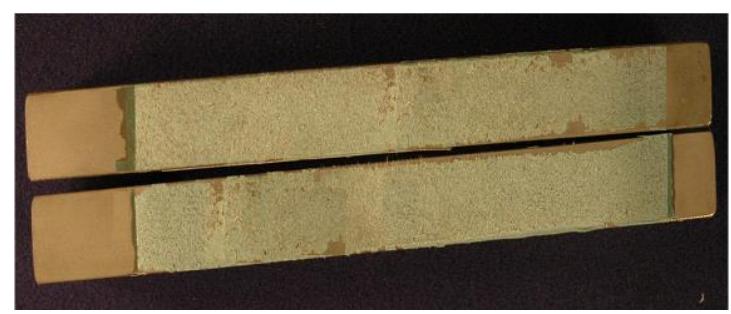

(c)Pure Mode II

Figure 12 Failure surfaces observed under different mode conditions

Test configurations and failure load data arranged in order of increasing mode II contribution are shown in Table 2, while Table 3 summarises energy release rate calculations corresponding to the configurations shown in Table 2. The energy release rate values are given for the analytical solutions, ignoring and including the bond-line correction, and from finite element analysis. 
Table 2 Test configurations and failure load data (arranged in order of increasing mode II contribution)

\begin{tabular}{|c|c|c|c|c|c|}
\hline $\begin{array}{c}\boldsymbol{S}_{1} \\
(\mathbf{m m})\end{array}$ & $\begin{array}{c}\boldsymbol{S}_{\mathbf{2}} \\
(\mathbf{m m})\end{array}$ & $\begin{array}{c}\text { Lower bar } \\
\text { connection point } \\
\text { Dimensions in } \mathbf{~ m m}\end{array}$ & $\begin{array}{c}\text { Specimen } \\
\text { Thickness }(\mathbf{m m})\end{array}$ & $\begin{array}{c}\text { Load ratio } \\
\boldsymbol{F}_{\mathbf{1}} / \boldsymbol{F}_{\mathbf{2}}\end{array}$ & $\begin{array}{c}\text { Failure } \\
\text { Load } \\
\boldsymbol{F}(\mathbf{N})\end{array}$ \\
\hline 100 & 100 & $\mathrm{C}\left(S_{3}=200, S_{4}=100\right)$ & 10 & -1 & 4508 \\
\hline 70 & 130 & $\mathrm{C}\left(S_{3}=200, S_{4}=100\right)$ & 10 & -1.86 & 3978 \\
\hline 133.3 & 66.7 & $\mathrm{C}\left(S_{3}=200, S_{4}=100\right)$ & 10 & -0.5 & 4267 \\
\hline 45 & 155 & $\mathrm{C}\left(S_{3}=200, S_{4}=100\right)$ & 10 & -3.44 & 3810 \\
\hline 200 & 0 & $\mathrm{C}\left(S_{3}=200, S_{4}=100\right)$ & 10 & 0 & 3423 \\
\hline 0 & 200 & $\mathrm{C}\left(S_{3}=200, S_{4}=100\right)$ & 10 & infinity & 3574 \\
\hline 0 & 200 & $\mathrm{D}\left(S_{3}=200, S_{4}=200\right)$ & 10 & infinity & 3374 \\
\hline 45 & 155 & $\mathrm{D}\left(S_{3}=200, S_{4}=200\right)$ & 10 & 6.89 & 4125 \\
\hline 70 & 130 & $\mathrm{D}\left(S_{3}=200, S_{4}=200\right)$ & 7 & 3.73 & 3694 \\
\hline 100 & 100 & $\mathrm{D}\left(S_{3}=200, S_{4}=200\right)$ & 7 & 2 & 3955 \\
\hline 133.3 & 66.7 & $\mathrm{D}\left(S_{3}=200, S_{4}=200\right)$ & 7 & 1 & 6518 \\
\hline 200 & 0 & $\mathrm{D}\left(S_{3}=200, S_{4}=200\right)$ & 7 & 0 & 7906 \\
\hline
\end{tabular}

Table 3 Summary of energy release rate calculations for the specimens shown in Table 2

\begin{tabular}{|c|c|c|c|c|c|c|c|}
\hline $\begin{array}{l}\text { Failure } \\
\text { Load } \\
F(N)\end{array}$ & $\begin{array}{c}\mathrm{GI}_{\mathrm{I}}, \\
\text { Eqn. (11) } \\
\mathrm{J} / \mathrm{m}^{2}\end{array}$ & $\begin{array}{c}G_{I I}, \\
\text { Eqn. (12) } \\
\mathrm{J} / \mathrm{m}^{2}\end{array}$ & $\begin{array}{c}G_{I}, \\
\text { Eqn. (14) } \\
\mathrm{J} / \mathrm{m}^{2}\end{array}$ & $\begin{array}{c}\mathrm{G}_{\mathrm{II}}, \\
\text { Eqn. (15) } \\
\mathrm{J} / \mathrm{m}^{2}\end{array}$ & $\begin{array}{c}\mathrm{GI}_{\mathrm{I}} \\
\mathrm{FEA} \\
\mathrm{J} / \mathrm{m}^{2}\end{array}$ & $\begin{array}{l}G_{I I}, \\
F E A \\
J / m^{2}\end{array}$ & $\begin{array}{c}G_{I I} / G_{I} \\
\text { Eqns. } \\
\text { (14) and } \\
(15)\end{array}$ \\
\hline 4508 & 806 & 0 & 1322 & 0 & 1348 & 0 & Mode I \\
\hline 3978 & 630 & 42 & 1034 & 70 & 1070 & 91 & 0.07 \\
\hline 4267 & 725 & 60 & 1188 & 102 & 1303 & 75 & 0.09 \\
\hline 3810 & 584 & 130 & 956 & 214 & 959 & 251 & 0.22 \\
\hline 3423 & 484 & 349 & 794 & 572 & 812 & 546 & 0.72 \\
\hline 3574 & 528 & 380 & 866 & 623 & 808 & 625 & 0.72 \\
\hline 3374 & 470 & 339 & 771 & 555 & 720 & 557 & 0.72 \\
\hline 4125 & 309 & 399 & 506 & 654 & 457 & 706 & 1.29 \\
\hline 3694 & 364 & 806 & 596 & 1321 & 491 & 1256 & 2.22 \\
\hline 3955 & 115 & 763 & 109 & 1252 & 143 & 1181 & 6.62 \\
\hline 6518 & 0 & 1639 & 0 & 2687 & 0 & 2507 & Mode II \\
\hline 7906 & 0 & 1356 & 0 & 2223 & 0 & 2074 & Mode II \\
\hline
\end{tabular}


From Table 3 it is clear that neglecting the bond-line thickness underestimates the results for both $G_{\mathrm{I}}$ and $G_{\mathrm{II}}$. Note that three sets of data are presented at a modemixity of 0.72 , while two sets of data are presented for mode II. This is because the design allows different configurations to apply some values of mode-mixity and this gives a further validation of the jig. The two load cases for mode II are shown in Figure 13. In case $1, F_{1}=F_{2}=F / 3$ and the total applied load on specimen is $2 F / 3$ while in case 2, $F_{1}=0$ and $F_{2}=F / 2$ hence the total applied load on specimen is $F / 2$. Therefore the total applied load at failure in these two situations is different (6518 N and $7906 \mathrm{~N}$ for case 1 and 2 respectively).
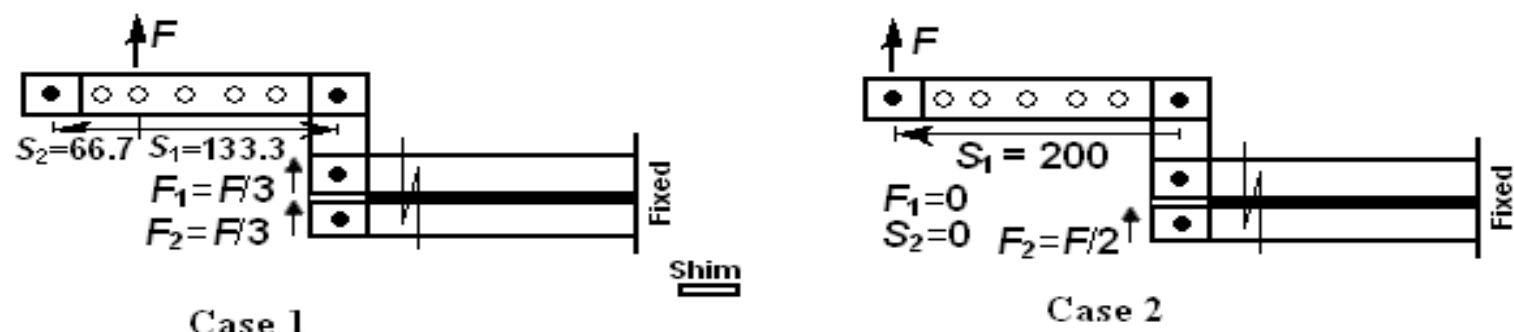

Case 2

Figure 13 Same effects (mode II) on identical specimens with different external load position pinning support $\mathrm{A}$ at $\mathrm{D}$ (as in figure 1)

Figures 14 and 15 show the results from all the specimens presented as plots of $G_{\text {II }}$ as a function of $G_{\mathrm{I}}$. In Figure 14 the comparison is made between the FEA results and the analytical solution neglecting the bond-line contribution. In Figure 15 the bond-line contribution is included. There should be nine different clusters of data apparent corresponding to the range of mode mixities, but in practice the data sets corresponding to $G_{\|} / G_{l}=0.07$ and $G_{\|} / G_{l}=0.09$ are in very close proximity. The data from the different test configurations that give $G_{I I} / G_{I}=0.72$ are in good agreement. It is clear from these figures (and from Table 3) that for the latter case there is very reasonable agreement between the analytical solution for the energy release rate components and the FEA results. When the bond-line tem is ignored, this leads to significant under-estimates of the strain energy release rates. 


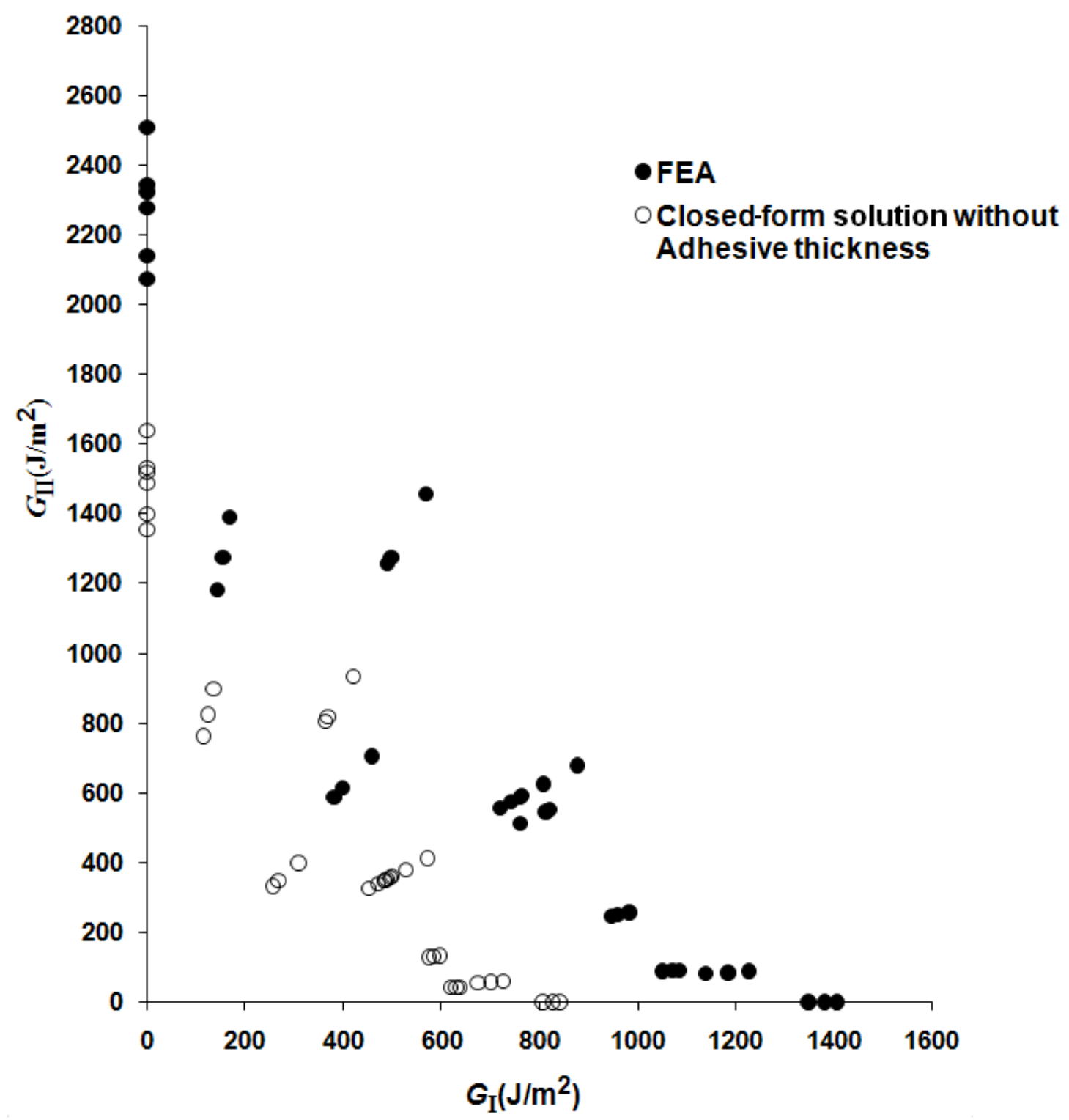

Figure 14 Mixed mode fracture data for DCB bonded joints subjected to mixed mode loading showing the experimental data analysed using closed-form analysis (neglecting bond-line contribution) and FEA 


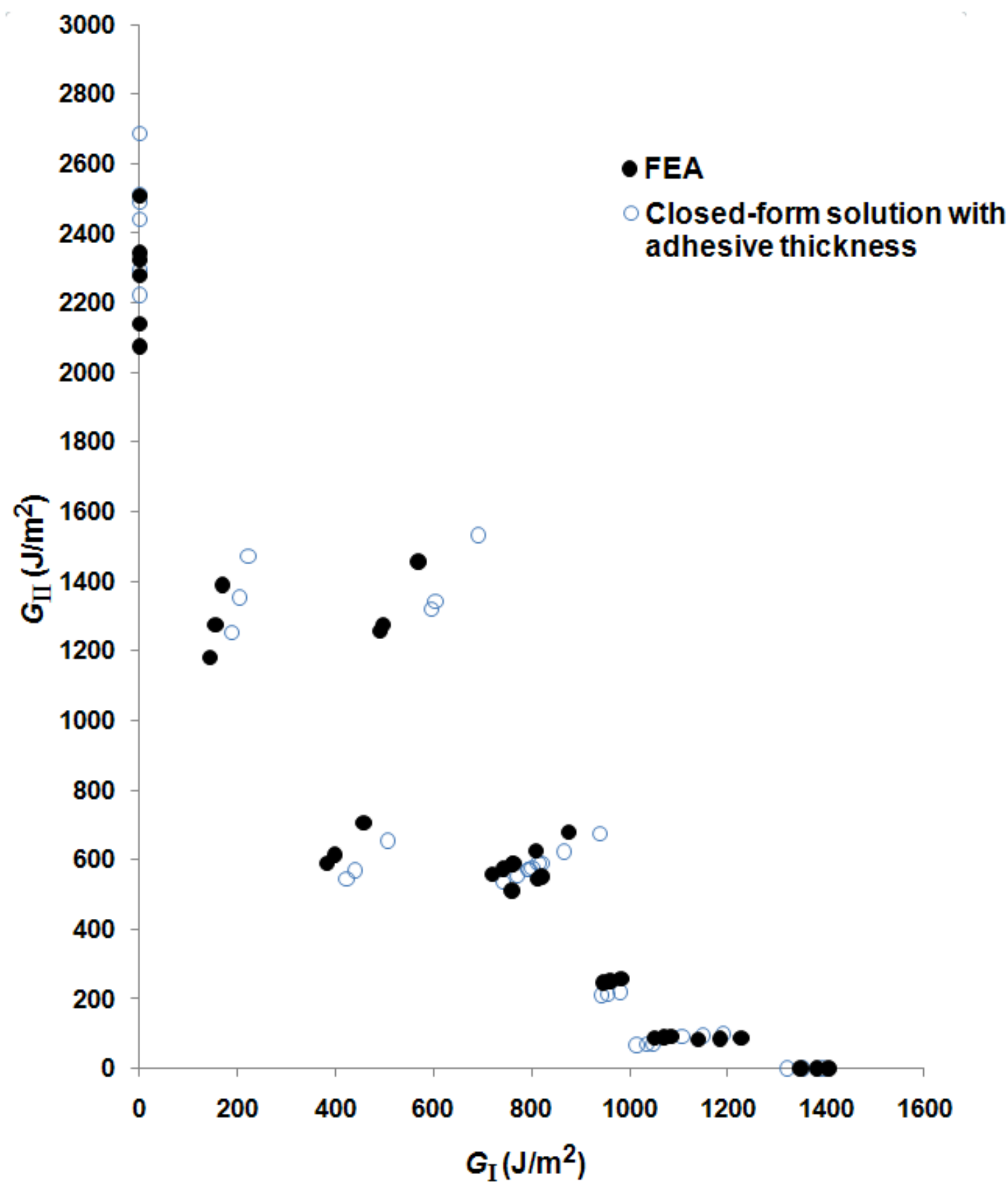

Figure 15 Mixed mode fracture data for DCB bonded joints subjected to mixed mode loading showing the experimental data analysed according to closed-form analysis (including bond-line contribution) and FEA 
While this range of mode mixities does not seem to have been covered by other researchers, there are data in the literature for $G_{I C}$ for FM-73M [18, 23-26] against which the present study can be compared. Published values range from $2000 \mathrm{~J} / \mathrm{m}^{2}$ [18] to a mean value of around $2800 \mathrm{~J} / \mathrm{m}^{2}$ from a number of studies [23-25] and a value of $3700 \mathrm{~J} / \mathrm{m}^{2}$. The values are based on various configurations and data reduction techniques. There may be a bond-line thickness effect as the lower value [18] is associated with a $0.2 \mathrm{~mm}$ bond-line with other studies using $0.25 \mathrm{~mm}$. In general the values have been determined from metal/adhesive specimens, although it is interesting to note that when Johnson et al [25] used an Aluminium/FM$73 \mathrm{M} /$ Boron-Epoxy system then the total fracture toughness obtained was only 840 $\mathrm{J} / \mathrm{m}^{2}$ which was significantly less than the value from Aluminium/FM-73M/Aluminium system. In the present work the mean $G_{I C}$ value was around $1400 \mathrm{~J} / \mathrm{m}^{2}$. This is low compared with other published values, but the bond-line thickness is smaller, which is expected to give rise to a lower toughness, and because of the particular joint geometry the details of the crack propagation mechanism (and associated toughness) may be different.

With regard to the trends on the $G_{l}-G_{\|}$plots, it is apparent that the presence of mode II generally reduces the level of the mode I energy release rate required to cause failure, i.e. there is a significant degree of interaction. There are some anomalies apparent around the data corresponding to $G_{\|} / G_{l}=1.29$ and $G_{\|} / G_{l}=2.22$, which require further work to resolve; otherwise the trends are reasonable.

\section{Concluding Remarks}

The present study has developed a simple experimental method for carrying out mixed mode fracture testing on adhesively bonded DCB specimens. The test method is supported by analytical and FEA results, which are in good agreement with each other provided that an allowance for the bond line deflection is made in the analytical expressions for the energy release rate components. The test method has been used successfully to investigate the mixed mode fracture envelope for FM-73M adhesive. It has been shown that there is considerable interaction between the modes of loading and that mode II fracture energy is considerably higher than mode 
I. The results from this work will be valuable in developing cohesive-element-based failure models for FM-73M adhesive.

\section{References:}

[1] Fernlund G, Spelt JK. Failure load prediction of structural adhesive joints: Part 2: Experimental study. Int J Adhes and Adhes 1991;11: 221-227.

[2] Hutchinson JW, Suo Z. Mixed-mode cracking in layered materials. Advances in Applied Mechanics 1992;29:63-191.

[3] Fernlund G, Spelt JK. Mixed-mode fracture characterization of adhesive joints. Comp Sci Tech 1994;50:441-449.

[4] Ripling EJ, Mostovoy S , Corten HT. Fracture Mechanics: A tool for evaluating structural adhesives. J Adhes 1971;3:107-123.

[5] Russell AJ, Street KN. Factors affecting the interlaminar fracture energy of graphite epoxy laminates. In: Progress in Sci \& Engg of Comp, ICCM-IV, NorthHolland, Amsterdam 1982; 279-286.

[6] Russell AJ, Street KN. Moisture and temperature effects on the mixed-mode delamination fracture of unidirectional graphite/epoxy. In: Delamination and debonding of materials, ASTM STP 876, W.S.Johnson Ed., American Society for Testing and Materials 1985; 349-370.

[7] Bradley WL, Cohen RN., Matrix deformation and fracture in graphite-reinforced epoxies. In: Delamination and debonding of materials, ASTM STP 876, W.S.Johnson Ed., American Society for Testing and Materials 1985; 389-410.

[8] Johnson WS. Stress analysis of the cracked-lap-shear specimen: an ASTM round-robin. J Test Eval 1987; 6: 303-324.

[9] Reeder JR, Crews Jr JH. The mixed-mode bending method for de-lamination testing, AIAA J 1990; 28:1270-1276.

[10] Hashemi S, Kinloch KJ, Williams JG. Mixed-mode fracture in fiber-polymer composite laminates. In: Delamination and debonding of materials, ASTM STP 1110, T.K.O`Brien Ed., American Society for Testing and Materials 1991;143-162. 
[11] Pang HLJ, Seetoh CW. A compact mixed-mode (CMM) fracture specimen for adhesive bonded joints. Engng Frac Mech 1997; 57:57-65.

[12] Choupani N. Mixed-mode cohesive fracture of adhesive joints: Experimental and numerical studies. Engng Frac Mech 2008;75:4363-4382.

[13] Marannano GV, Mistretta L, Cirello A, Pasta S. Crack growth analysis at adhesive-adherent interface in bonded joints under mixed-mode I/II. Engng Frac Mech 2008;75:5122-5133.

[14] Williams JG. On the calculation of energy release rate for cracked laminates. Int J Frac 1988;36:101-119.

[15] Mostovoy S, Ripling EJ. Flaw tolerance of a number of commercial and experimental adhesives. J Adhes Sci Tech 1975;9:64-80.

[16] Pirondi A, Nicoletto G. Fatigue crack growth in bonded DCB specimens. Engng Frac Mech 2004;71:859-871.

[17] Liljedahl CDM, Crocombe AD, Wahab MA and Ashcroft IA, Damage Modelling of Adhesively Bonded Joints. Int J Fracture 2006;141-1:147-161

[18] Shenoy V, Ashcroft IA, Critchlow GW, Crocombe AD. Prediction of fatigue damage and crack growth in adhesively bonded joints using progressive damage methods. Int J Solids Struc 2010; in press.

[19] Sethuraman R, Maiti SK. Finite element based computation of strain energy release rates by modified crack closure integral. Engng Frac Mech 1988;30:227-231.

[20] Barsoum RS. On the use of isoparametric finite elements in linear fracture mechanics. Int J Num Meth Engng 1976;10:25-37.

[21] Abdel Wahab MM. On the use of fracture mechanics in designing a single lap adhesive joint. J Adhes Sci Tech 2000;14:851-865.

[22] User manual, Instron 5500R, frame 1175.

[23] Khoramishad $H$, Crocombe $A D$, Katnam $K B$ and Ashcroft IA. A generalised damage model for constant amplitude fatigue loading of adhesively bonded joints. Int J Adhesion and Adhesives 2010; 30:513-521 
[24] Ripling EJ, Crosley PB , Johnson WS. A comparison of pure mode I and mixed mode I-III cracking of an adhesive containing an open knit cloth carrier adhesively bonded joints: Testing, Analysis and Design. In: ASTM STP 981, Philadelphia, USA: American Society for Testing and Materials 1988; 163-182.

[25] Johnson WS, Butkus LM, Valentin RV. Application of fracture mechanics to the durability of bonded composite joints. Report No. DOT/FAA/AR-97/56, May 1998.

[26] Jastrzebski MU, Sinclair AN, Raizenne DD, Spelt JK. Development of adhesive bonds with reduced fracture strength as NDE benchmarks. Int $\mathrm{J}$ Adhes Adhes 2009;29:372-379. 